\title{
Evaluation of satellite-derived burned area products
for the fynbos, a Mediterranean shrubland
}

\author{
Helen M. de Klerk ${ }^{\mathrm{A}, \mathrm{B}, \mathrm{E}}$, \\ Adam M. Wilson ${ }^{C}$ and Karen Steenkamp \\ Matieland, 7602, South Africa,
${ }^{3}$ Western Cape Nature Conservation \\ 7599, South Africa.
CDepartment of Ecology and Evolutionary Bioger, Scientific Services, P Bag x5014, Stellenbosch, \\ Eagleville Road, Unit 3043, Storrs, CT 06269-3043, USA. \\ DCouncil for Scientific and Industrial Reserch 06269 , USA. \\ Pretoria 0001, South Africa. \\ ${ }^{E}$ Corresponding author. Email: hdeklerk@sun.ac.za
} \begin{abstract}
Fire is a critical ecological process in the fynbos of the south-western area of South Africa, as it is for all dwarf
Mediterranean shrublands. We evaluated the potential of current publicly available MODIS burned area products to
contribute to an accurate fire history of the fynbos. To this end, we compared the Meraka Institute's MODIS
product, based on the Giglio algorithm (termed the 'WAM area product, based on the Roy algorithm, with 'WAMIS' product) as well as the standard MODIS MCD burned area inventory accuracy assessment (numberithm, with comprehensive manager-mapped fire bound MODIS MCD45A1 burned showed promise for both bured amber and size of individual burn scars) and fire boundary data. We used standard commission (8.1-19.1\%) and high area products, depending on the intended use. The MCD it useful for studies that need to consumer's accuracy $(80.9-91.9 \%)$, but relatively The MCD45A1 had low errors of generally had low errors of to identify burned pixels with a high degree of cerly common errors of omission, making for supplementing manager-mapped fi.2-43.8\%) and greater producer's accuracy $(56.2-87.6 \%)$, the WAMIS product , especially for fynbos remnants occurring outside protected areas.
\end{abstract}

Manuscript received 8 January 2011, accepted 2 May 2011
Published online $x x$ xxxxx xxxx

\section{Introduction} Fire is an important ecological process in more than $50 \%$ of the
world's terrestrial ecosystems (Shlisky et al. 2009); the natural of anthropogenic influences (Shlisky been altered because use and climate chences (Shlisky et al. 2007). Future land fire regimes globally (Ds likely to continue to affect changes in accurate mapping of firesman et al. 2007, section 7.3.3.1.4), so our understanding of the through space and time is critical for at regional to global scales. Knowled and ecological dynamics affected by the fire and the burned area is and how the effect of the fire varied across ment actions, guide future ensary in order to appraise manage2010) and

Field mappingo be required for legal purposes.

large fires or fire of fires is time consuming and costly and for to accurately fires in remote and inaccessible areas, it is difficult arises as to map the full extent of a burned area. The question burned area products assist in assist in accurately mapping burned areas. Currently, burned area products are primarily used at regional to global scales for exercises such as fire emissions modelling (Roy and Boschetti 2009). They are also occasionally used for local scale ecological 2009). Lource management applications (Roy and Boschetti an important step to test the accuracy of these products are at the regional in evaluating the usefulness of these products frequentlon and global scales at which they are frequently used. Published evaluations show that satellite world, including area products are useful for many parts of the (Giglio et al. Eastern Russia (Sukhinin et al. 2004), Siberia States (Li et al. 2003) North America and the western United (Díaz-Delgado and Giglio et al. 2009), Mediterranean regions (Diaz-Delgado and Pons 2001; Chuvieco et al. 2005) and 2005b: Giglica (Trigg and Flasse 2001; Roy et al. 2005a, the ability of satell. 2009; Roy and Boschetti 2009). However, events and the accule-derived burned area products to detect fire events and the accuracy with which they can map the fire can vefore, widely depending on local conditions and vegetation, before, during and after a fire event (e.g. de Klerk 2008; Roy and Boschetti 2009). Hence, evaluation of the products for for a specific re re needed before acceptance of a model output for a specific region (e.g. Roy and Landmann 2005). 
As in many Mediterranean ecosystems, fire in the dwarf Mediterranean shrubland typical of the fynbos (Rebelo et al. 2006 ) is a vital ecological process and important for conservation management (Cowling 1987; Richardson et al. 1994; Bond and Keeley 2005). The fynbos biome, which occurs in the mainly winter rainfall region of the south-western tip of South Africa (Rebelo et al. 2006), is not only highly fire prone, but is fire adapted and needs periodic fire to reproduce (e.g. Keeley and Bond 1997; Rebelo et al. 2006). The fynbos biome covers a geographically small area, but is of great conservation importance owing to its high levels of species richness and endemism (these aspects are thoroughly discussed by Rebelo et al. 2006). Wilson et al. (2010) and van Wilgen et al. (2010) suggest that the south-western Cape is vulnerable to changes in the fire regime driven by human activity and climate change.

Fynbos is structurally and spectrally different from grassland and miombo (Wessels et al. 2010) where most testing of satellite burned area algorithms has been conducted (e.g. Trigg and Flasse 2001; Roy et al. 2005a, 2005b; Giglio et al. 2009). In addition, the fynbos biome includes areas of topographically complex landscapes where shadowing may affect the accuracy of the reflectance values reaching the satellite (de Klerk 2008). Glint from extensive coastlines and light soils can also lead to spurious reflectance measurements (de Klerk 2008). The Western Cape Nature Conservation Board (CapeNature) manages formally protected areas of the Western Cape of South Africa, many of which fall within the fynbos biome. Good datasets of fire boundaries mapped by operational fire agencies in the field, which we refer to as manager-mapped fire boundaries, are available for these protected areas (see full description in 'Materials and methods') (de Klerk 2008; van Wilgen and Forsyth 2008). This enabled us to test the Meraka Institute's new MODIS burned area product, based on the Giglio et al. (2009) algorithm released late in 2009, as well as the MCD45A1 burned area product, based on the Roy et al. (2005a) algorithm, for which data are available on the MODIS website.

In this study, we compared the two MODIS-derived products in the formally protected areas within the fynbos and succulent karoo biomes (Mucina and Rutherford 2006) with carefully mapped fire boundaries produced by reserve managers (see de Klerk 2008 for details of the database). General validation methods (after Giglio et al. 2009; Roy and Boschetti 2009) were used and included (1) an inventory accuracy assessment of the number and size of individual burn scars mapped by the reference and classified datasets; and (2) a subset of standard confusion matrix parameters, which provided a per pixel evaluation of the spatial fidelity of a classification's accuracy.

The additional question of whether these products can be used as a 'reliable' surrogate for mapping burned areas outside of formally protected areas, where currently there are no analogue fire history records available, was also an important one, with landscape conservation initiatives on private land increasing in the Western Cape (CapeNature 2009).

\section{Materials and methods}

Study area and protected area data

CapeNature (http://www.capenature.co.za/, accessed 12 August 2011) manages formally protected areas of the Western Cape of
South Africa, namely Provincial Nature Reserves (International Union for the Conservation of Nature and Natural Resources, IUCN, Category II), State Forests (also IUCN Category II), Wilderness Areas (IUCN Category I) and privately owned mountain catchment areas; the latter being jointly managed by CapeNature and private landowners (see Fig. 1). These areas are collectively referred to as 'protected areas'.

\section{Burned'area - reference data from reserve managers}

Fire boundaries are currently mapped by CapeNature reserve managers for all fires on all land managed by CapeNature, as described above (Erasmus 2006). Managers and field staff map fire boundaries during fire operations, as well as during post fire debriefing. They use a combination of analogue mapping onto paper maps; 'heads-up digitising', that is, digitising geographic features directly onto computers using digital topographical maps, satellite images (LANDSAT and SPOT) and aerial photos; as well as walking or flying the fire boundary with a global positioning system (GPS). Information from these various sources is used by the managers to produce a final vector file (ESRI shapefile format). Islands of unburned vegetation within the outer boundary of the fire are digitised as such. All fire reports and associated polygon data are lodged in a central fire database housed at CapeNature's Scientific Services. These data are referred to as manager-mapped boundaries. Updates of this fire data are provided annually for public use on the Biodiversity GIS website (http: Ilbgis.sanbi.org, accessed 12 August 2011). Manager-mapped burned area boundaries were extracted for the time period of 1 September 2007 to 30 April 2009, in order to cover two fire seasons in the fynbos biome. Data were available for all datasets considered for this period at the beginning of the present study. Two fire seasons allowed careful checking of results for inconsistencies and errors that may have been more difficult to identify for an analysis of many years. Broadly speaking, the fire season in the fynbos extends from September in one calendar year to April in the next calendar year (Wilson et al. 2010).

In order to investigate the influence of the difference in spatial resolution between the manager-mapped fire boundaries and the MODIS-derived burned area products, the managermapped fire boundaries needed to be 'degraded' to the same scale as the burned area rasters. The manager-mapped fire boundaries were overlaid on the 'WAMIS grid' (see below). Where the manager-mapped fire boundaries covered at least $50 \%$ of a pixel, the pixel was identified as a 'manager-mapped burned pixel'. The latter grid was vectorised for the purposes of overlay analyses and is referred to as 'manager-mapped gridded boundaries'. We analysed the difference between the original (ungridded) and gridded manager data and we found very little difference in the metrics (see 'Evaluation of performance' for details on these metrics) (data not shown). Consequently, only the results for the original (ungridded) manager-mapped boundaries are displayed.

\section{Burned area - WAMIS/Giglio algorithm datasets}

The Meraka Institute in South Africa (http://www.csir.co.za/ meraka/, accessed 12 August 2011) released a new MODISderived burned area product, based on the Giglio et al. (2009) 


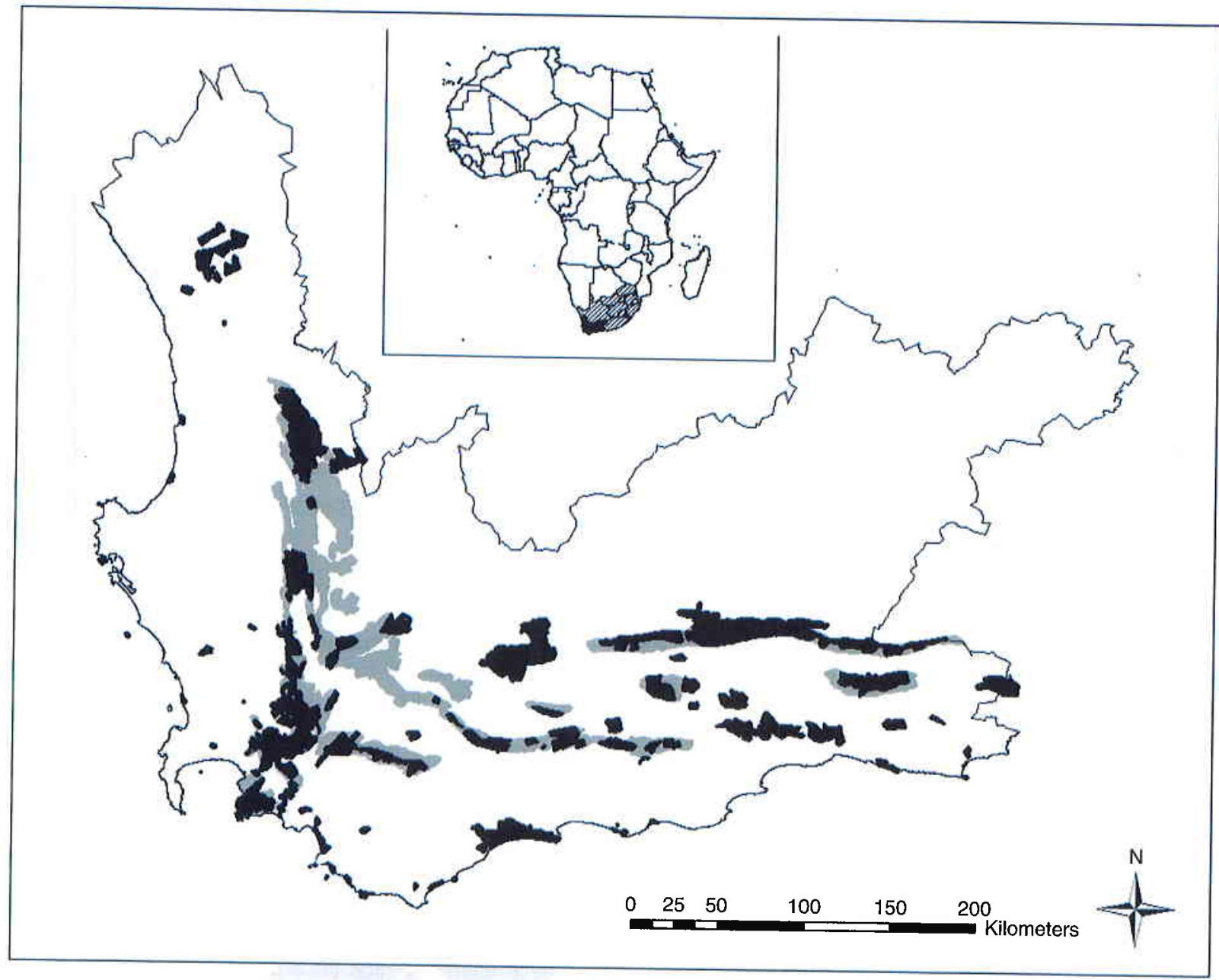

Fig. 1. Land managed for conservation purposes by CapeNature, which includes statutory Provincial Nature Reserves (International Union for the Conservation of Nature and Natural Resources, IUCN, Category II), State Forests (also IUCN Category II) and Wilderness Areas (IUCN Category I) (solid black) as well as privately owned, proclaimed Mountain Catchment Areas (solid grey). The insert shows the location of the Western Cape Province (solid black) in South Africa (hashing). Data for this figure are in UTM 34 S (central meridian, 21; reference latitude, 0; scale factor, 0.9996; false easting, 500000; false northing, 10000000 ) and WGS84 (Hartebees94) datum.

algorithm, late in 2009. For brevity, this product is henceforth referred to as the 'WAMIS' burned area product. The following description is summarised from Giglio et al. (2009). The algorithm uses actual vegetation change by compiling a vegetation index. It then seeks a large, rapid decrease in the vegetation index relative to the variability of this vegetation index over the same time series of images. Information on persistent changes in this burn-sensitive vegetation index are combined with active fire maps through the use of many screening processes, regional cluster growing, probability density functions and a temporal texture measure. The inclusion of active fire maps and the use of probability density functions based on these active fire maps, allows this hybrid algorithm to function robustly over a wide range of biomes to identify both burned and unburned pixels with greater accuracy for training the algorithm. The regional growing phase allows good performance in large burned areas. The WAMIS burned area tiff images were downloaded from the
South African Council for Scientific and Industrial Research (CSIR, http://www.csir.co.za, accessed 12 August 2011), Meraka Institute's Wide Area Monitoring Information System (WAMIS) website (http://www.wamis.co.za, accessed 12 August 2011) for the period from 1 September 2007 to 30 April 2009.

\section{Burned area - MCD45A1/Roy algorithm datasets}

The MODIS/Terra+Aqua Burned Area Monthly L3 Global $500 \mathrm{~m}$ SIN Grid V005 (or MCD45A1) product hdf images were downloaded for the same dates from http://wist.echo.nasa.gov (accessed 12 August 2011). MCD45Al is a monthly Level-3 gridded $500-\mathrm{m}$ product that maps the approximate day of burning for and extent of recent fires (MODIS Collection 5 Burned Area Product; Boschetti et al. 2009; http://modis-fire. umd.edu/BA_methodology.html, accessed 12 August 2011). It is based on the premise that burned areas are characterised by 
deposits of charcoal and ash, removal of vegetation and an altered vegetation structure (Roy et al. 1999). Multi-temporal land surface reflectance data are used to locate rapid changes in the daily surface reflectance dynamics through the use of a bidirectional reflectance distribution function (BRDF) model (Roy et al. 2005a). The algorithm is applied independently to geolocated $500-\mathrm{m}$ pixels (Boschetti et al. 2009). A statistical measure of the difference between the observed BRDF values and the predicted BRDF values, per pixel, at the viewing and illuminating angles of the observation, is used to quantify change from a previously observed state (Roy et al. 2002, 2005a; Boschetti et al. 2009). Large discrepancies between predicted and measured values are attributed to change (Roy et al. 2005a). A temporal constraint is used to differentiate between temporary changes, such as shadows, that are spectrally similar, from more persistent fire induced changes (Roy et al. 2005a)

All data were reprojected to UTM $34 \mathrm{~S}$ (central meridian, 21; reference latitude, 0 ; scale factor, 0.9996; false easting, 500000 ; false northing, 10000000 ) and WGS84 (Hartebees94) datum, resampled to a grid cell size of $463.31 \mathrm{~m}$, using one of the WAMIS images as a 'master grid' to ensure exact co-registration among all datasets. All area calculations were performed in UTM $34 \mathrm{~S}$, as this provided good aerial and distance accuracy across the study area of the Western Cape. All grid cells that fell outside of formally protected areas in the Western Cape Province were ignored for these analyses, as manager-mapped burned area data are available only inside protected areas.

\section{Evaluation of 'performance'}

We were interested in the ability of the satellite products to accurately (1) identify burned areas and measure their size; and (2) map their boundaries. Our evaluation consisted of an 'inventory' analysis that identified whether a particular fire event was mapped by all databases and compared the sizes of individual fires with a least-squares regression, as well as a confusion matrix that assessed geographic accuracy.

The inventory accuracy assessment was produced by comparing the proportion of burn scars in the manager-mapped data that were identified by the classified datasets (termed 'detection ability' and calculated as the number of burn scars in the classified datasets divided by the number in the managermapped data) and by comparing the sizes of individual burned areas in manager-mapped and classified datasets using the coefficient of determination $\left(R^{2}\right)$ (e.g. Giglio et al. 2009; Roy and Boschetti 2009). The size comparisons were calculated first for all fires that occurred in either or both datasets (termed 'all fire events'), and then for those fires that occurred only in both datasets (termed 'shared fire events').

A confusion matrix provides a geographic accuracy assessment by evaluating the spatial fidelity of mapping on a per pixel basis (e.g. Giglio et al. 2009; Roy and Boschetti 2009). The confusion matrix is a standard technique used to compare a classified image against a set of reference data (e.g. Campbell 1996). Although compilation of the error matrix is generally straightforward, preparation of the maps for comparison may be difficult (Campbell 1996). There are many measures that can be derived from a confusion matrix and it is suggested that a suite of measures be used to examine different aspects of the performance of a classification technique (e.g. Manel et al. 2001). We calculated the following parameters (definitions loosely from work by Campbell 1996), namely (i) percentage errors of omission (false negatives), which indicates how much the classification misses; (ii) percentage errors of commission (false positives), which indicates where the classification overmaps, or identifies fires not mapped by managers; (iii) producer's accuracy, which is the proportion of reference area in a class correctly classified in the output image; and (iv) consumer's accuracy, which is the proportion of the classification area in a class correctly classified in the output image. The consumer's accuracy showed reliability of the map as a predictive device and gave the probability that the pixels had been correctly assigned in the output classified map. Specificity indicated how accurately negative values were predicted (Fielding and Bell 1997; Manel et al. 2001). The confusion matrices were calculated for 'all fire events'.

The aim of the study was to compare burned area data from publicly available, standardised satellite products with managermapped burned areas. As managers map fires only within protected areas in our region, the study area was all protected area $(265330 \mathrm{ha})$. Consequently, the area that had not been burned in an evaluation period was always likely to be considerably larger than the area that had been burned during that same period, owing to the logical definition of the area of interest. For example, in 2008, 11264 ha burned inside these protected areas, which is only $4 \%$ of the protected areas, leaving most of the study area 'unburned'. This creates a large unburned class that is much easier to identify than burned areas, even though the latter were the main subject of the classification. This is akin to the situation where a map contains a large proportion of open water, a class that is easy to classify, resulting in a high 'percentage correct' value regardless of the performance of the classification in other class(es) (Campbell 1996). In addition, the existence of a large unburned class created vastly uneven sample sizes, which may have affected various measures, such as the Kappa statistic (Fielding and Bell 1997). Furthermore, the absence of detected fires at a particular location did not guarantee that the location did not burn (Giglio et al. 2009). In this study, the manager-mapped burned area boundaries were highly accurate owing to the manual effort using the variety of methods described above and because the accuracy of the boundaries has legal implications for CapeNature. However, we cannot be absolutely certain about the accuracy of these boundaries. These factors must be considered when interpreting measures that use 'true negatives' (putatively correctly identified unburned areas), as they could falsely inflate confidence in results.

All analyses were performed in ArcGIS 9.3 (Redlands, CA, USA) and MS Excel 2007. Data were analysed per year to provide more detailed insights of errors of omission and
commission.

\section{Results}

WAMIS

The correlation between the sizes of burned areas mapped by managers and the WAMIS product appeared to be strong $\left(R^{2}=0.84-0.87\right.$, Fig. 2, although for the $\log _{10}$-transformed $\mathrm{AQ1}$ data $R^{2}$ values were low when 'all fire events' were analysed). 

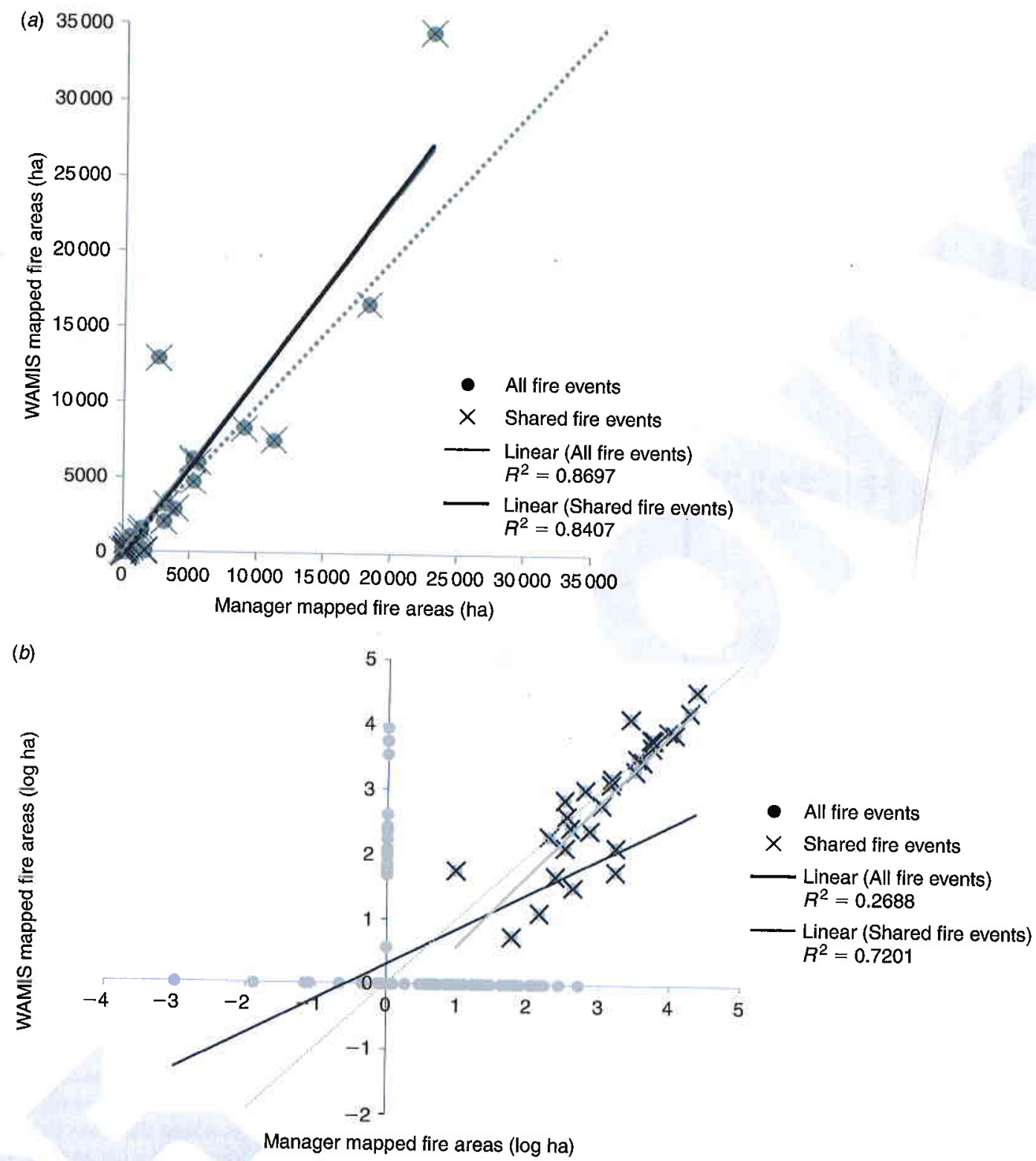

Fig 2. Regression of the area of individual fire events, mapped as burned areas by reserve managers (reference dataset) and the WAMIS product, with $(a)$ linear and $(b) \log _{10}$-transformed axes. The least-squares regressions are presented as solid lines. The dashed
$1: 1$ line indicates perfect agreement.

Several fire:events that were mapped by the managers were not mapped by WAMIS (see the low values of $33.3-43.1 \%$ for detection ability, Table 1). Note that although several points lie on the $1: 1$ perfect agreement line, there are a few notable exceptions.

The results of the confusion matrix (producer's accuracy, consumer's accuracy, errors of commission and omission) varied considerably between years. In general, errors of omission, that is fires mapped by managers which were missed, or under-mapped, by the WAMIS product, were low $(12.2-24 \%$, Table 1) in 2007 and 2009, owing to good spatial match between
WAMIS and manager-mapped boundaries for large fires in the Jonkershoek-Hottentots Holland area in February 2009 (Fig. 3a) and the Cederberg fire in February 2009 (Fig. 3b). However, values were higher in 2008 owing to under-mapping of certain fires, e.g. the southern Cederberg in February 2008 (Fig. 3c), as well as the WAMIS product missing several small to medium fires that had complex boundaries and occurred in topographically complex areas, such as Grootvadersbosch (1705 ha), Riviersonderend (1695 ha; Fig. $3 d$ ) and Limietberg (516 ha).

Errors of commission, that is fires that were identified by the WAMIS product but which were not mapped by the managers, 


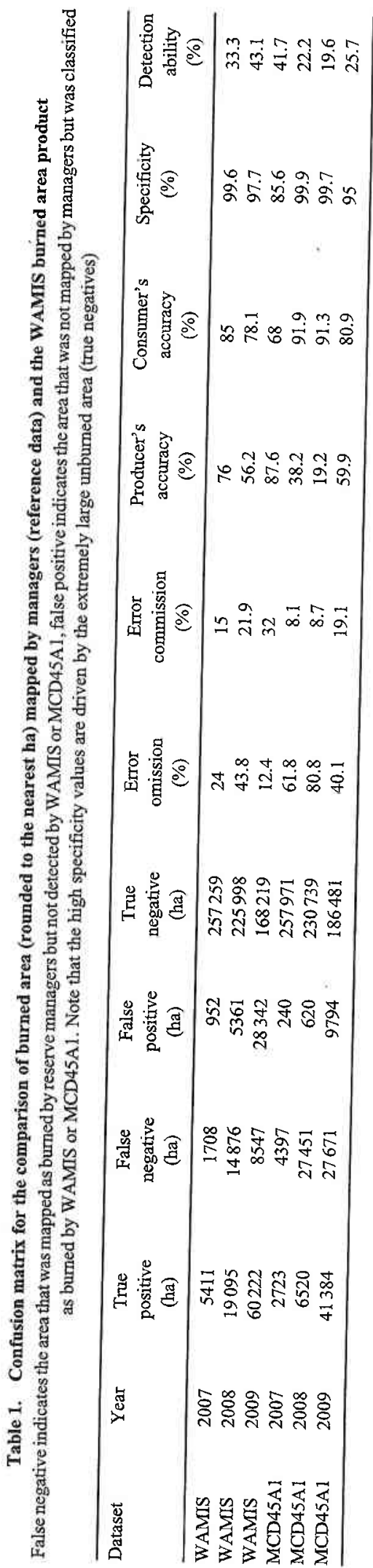

or where burned areas were either under-mapped by the managers or over-mapped by the WAMIS product, were generally low (14.6-23.4\%, Table 1). An exception was 2009 (31.9-32.8\%, Table 1$)$, when managers possibly under-mapped a fire in the GrootWinterhoek by a substantial amount (Fig. 3e)

Low omission and commission and good spatial match as described above, led to overall good values for both producer and consumer accuracy (which varied from 56.2 to $87.6 \%$, Table 1).

\section{MCD45A1}

The MCD45A1 product mapped burned areas conservatively. For example, in 2007, managers mapped an area of 7119 ha, whereas MCD45Al mapped an area of only 2962 ha, giving large errors of omission (40.1-80.8\%; Table 1). This was because MCD45A1 under-mapped several fire events (e.g. the Cederberg February 2009 fire Fig. $3 b$ ) and missed a few fire events, (see the data points lying on the $x$-axis indicating manager-mapped fires that MCD45A1 did not identify, Fig. 4b) as well as having low percentages of detection ability, Table 1). The reverse scenario was seen in one instance where managers under-mapped a fire in 2009 in the GrootWinterhoek, which WAMIS also identified as being considerably larger than the area mapped by the managers (Fig. 3e). The MCD45Al product seldom identified a burned area that did not burn, leading to very low errors of commission of $8.1-19.1 \%$ (Table 1) and high consumer's accuracy of 80.9 to $91.9 \%$ (Table 1). There were no areas identified as burned areas by MCD45A1 that were not also mapped by the managers and this may be responsible for the fairly strong regression values $\left(R^{2}=0.76-0.80\right)$, even though few data points are on the $1: 1$ line representing perfect agreement between the test and validation datasets.

\section{Discussion}

The high levels of omission seen in MCD45A1 compared with WAMIS (40.1-80.8\%, v. 12.4-43.8\%, Table 1; see fewer points along the $x$-axis in Figs 2,4) were expected because of the approach of the MCD45Al product (e.g. Roy and Boschetti 2009). MCD45A1 aims to map burned areas conservatively, in that it specifically aims to reduce errors of commission by 'only selecting fire affected pixels where there are burn candidates that provide persistent evidence of fire occurrence' (Roy et al. $2005 a$ ). Roy et al. (2005a) observed that this leads to larger errors of omission and that fires may be missed or under-mapped when small, particularly at the start of a fire and at the edges of large fires. The latter(ssue is because of strict implementation of the temporal consistency constraint (Roy et al. 2005a). The algorithm does try to adjust for this by using strong fire affected candidate pixels as seed pixels from which neighbouring pixels can obtain an increased burn probability (Roy et al. 2005a). In addition, these authors suggest that a relaxation of the temporal consistency constraint could be applied to reduce 'false rejections' of burned pixels, but perhaps the temporal consistency constraint is still too strong, as many MCD45A1 fires miss both initial days of the fire as well as boundary pixels (e.g. Fig. 3a). Perhaps the adaptation of the temporal thresholds for regional application, as suggested, applied in specific cases (Roy et al. $2005 a$ ), may improve on the error of omission rate and the 
(a)

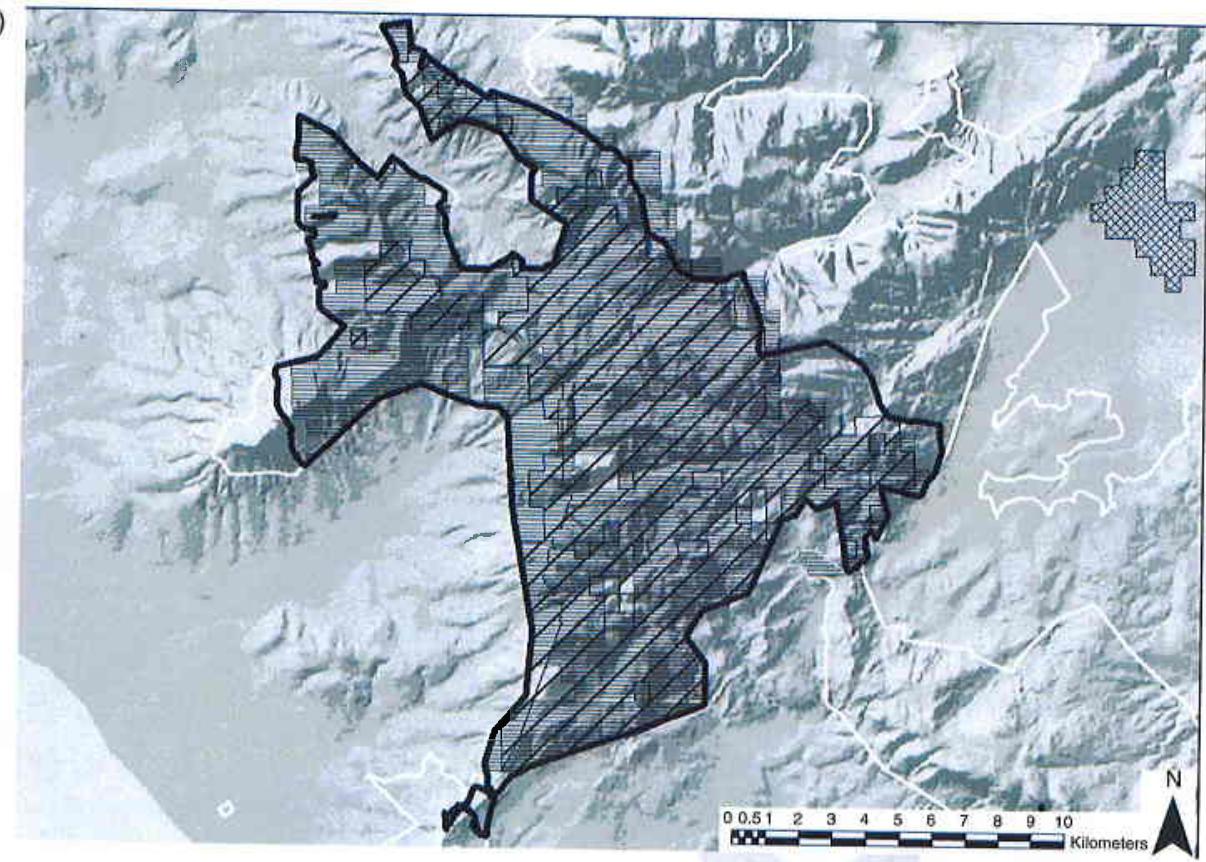

(b)

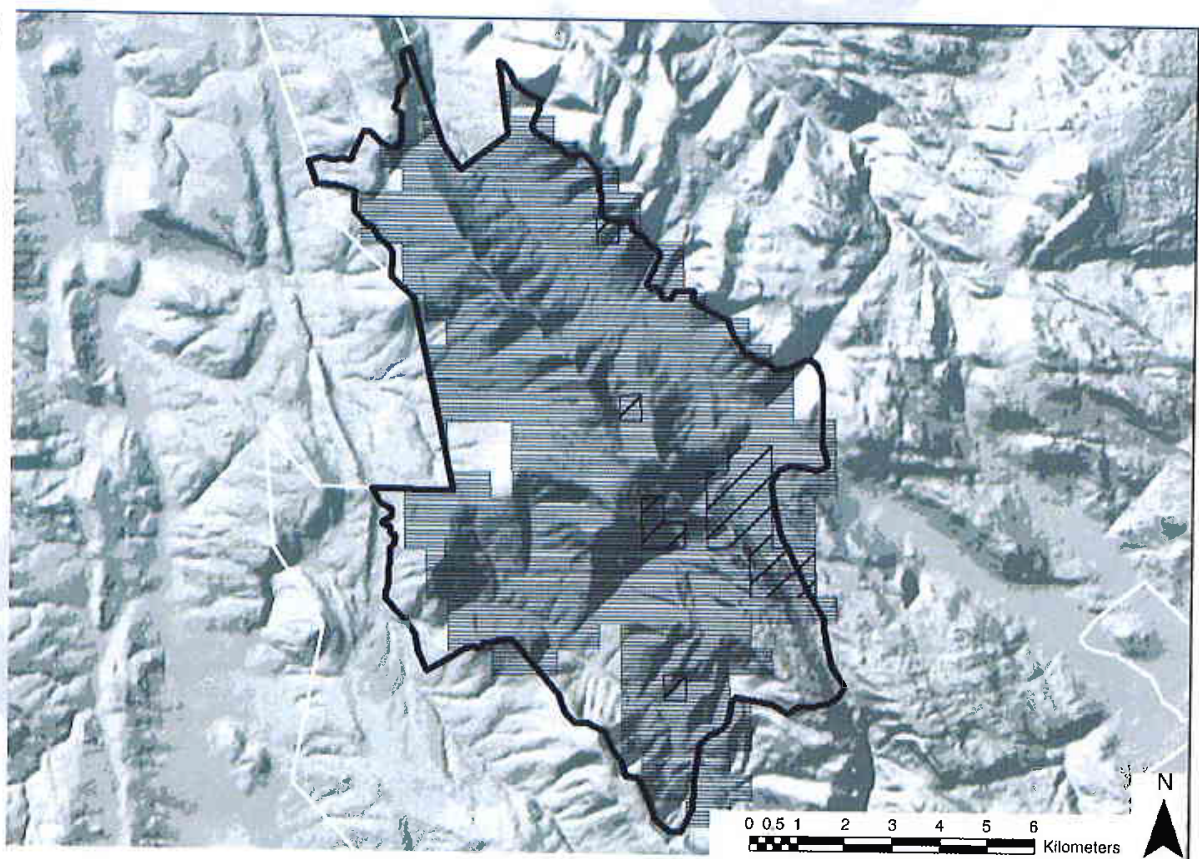

Fig. 3. Differences between burned areas mapped by the managers (black line) and the WAMIS product (horizontal hashing) and the MCD45A1product (diagonal hashing); where WAMIS maps a very similar fire extent to the managers in (a) Jonkershoek and (b) Cederberg fires in February of 2009; (c) where WAMIS undermaps the fire extent mapped by managers in the southern Cederberg fire in February 2008; and $(d)$ where WAMIS misses small fires mapped by managers, such as the 274 ha that burned in GrootVadersbosch in October 2008. (e) A case where both satellite burned area products (WAMIS and MCD45A1) show a larger area than mapped by the managers is seen in the Groot Winterhoek fire of February 2009. Protected Area boundaries are in white.

producer's accuracy. The algorithm contends yith low combustion completeness (i.e. when a cool fire doesn't burn all plant material in the burned area) or when a fire is smaller than a MODIS 500-m pixel and at land-water interfaces (Roy et al.
$2005 a$ ). Moreover, the algorithm appears to be very reliant on the post fire presence of black ash and the authors comment that this may pose a problem when 'more reflective underlying surfaces (in MODIS bands 2, 5 and 6) are exposed by the action 
(c)

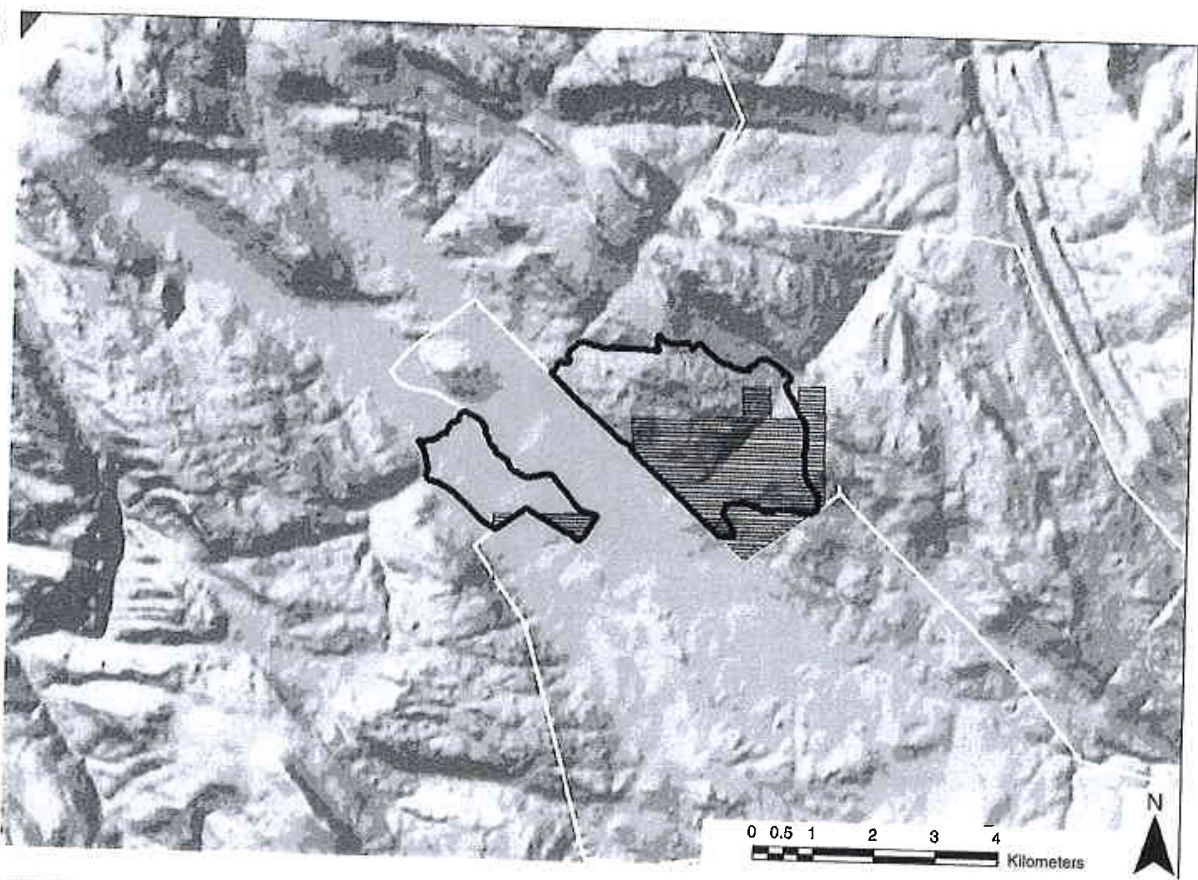

(d)

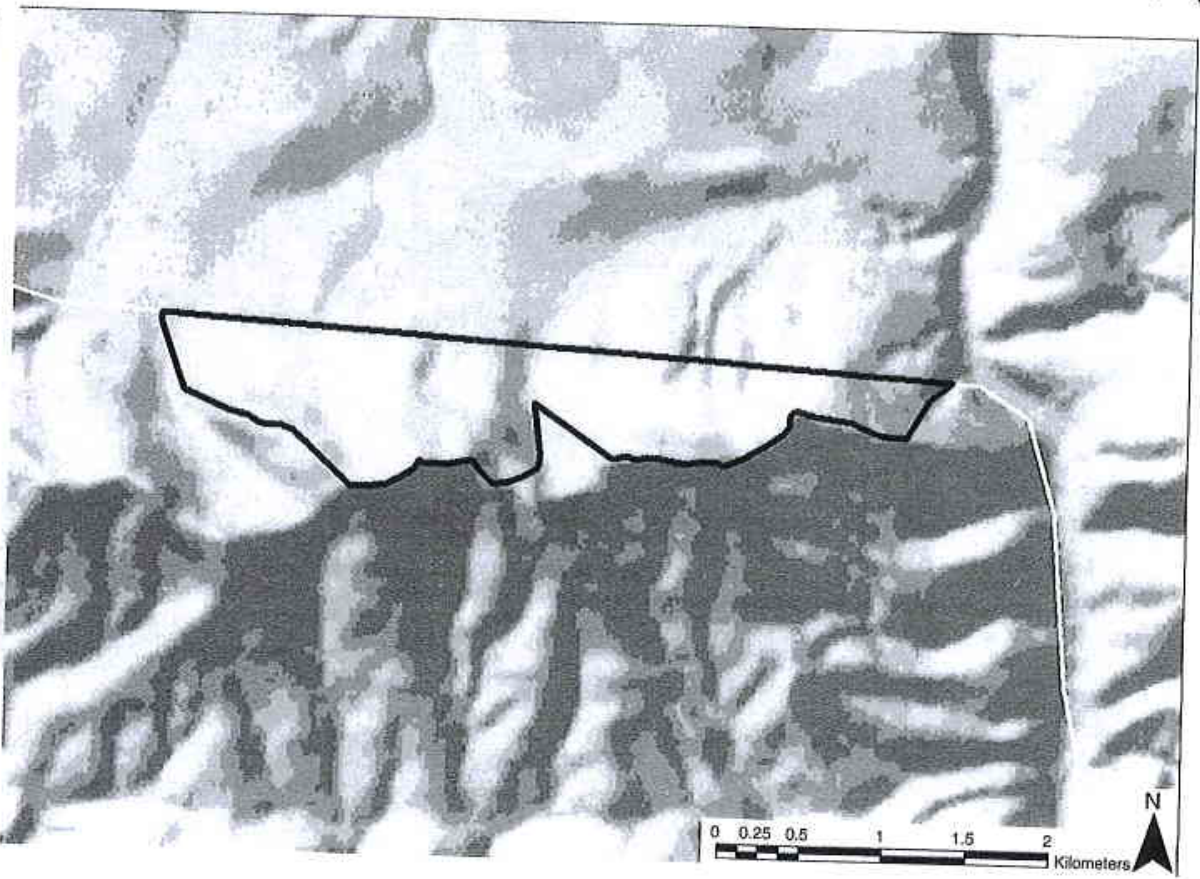

Fig. 3. (Continued)

of fire' (Roy et al. 2005a). Such an instance will arise when the fire occurs on highly reflective soil (de Klerk 2008). Similarly, this may occur when hot fires produce highly reflective white ash (Roy and Landmann 2005). If wind and rain dissipate the ash and charcoal rapidly after the fire, the post/fire reflectance values may be higher than the algorithm anticipates (Roy et al.
$2005 b$ ). The Roy algorithm is more likely to detect fires on surfaces that have a high pre-fire reflectance than on less reflective surfaces because it seeks large changes in reflectance from pre-burn state (mainly of dry grass) to black ash (Roy and Landmann 2005). This may explain why the MCD45A1 algorithm does a poorer job in the Cederberg, where the preffire 
(e)

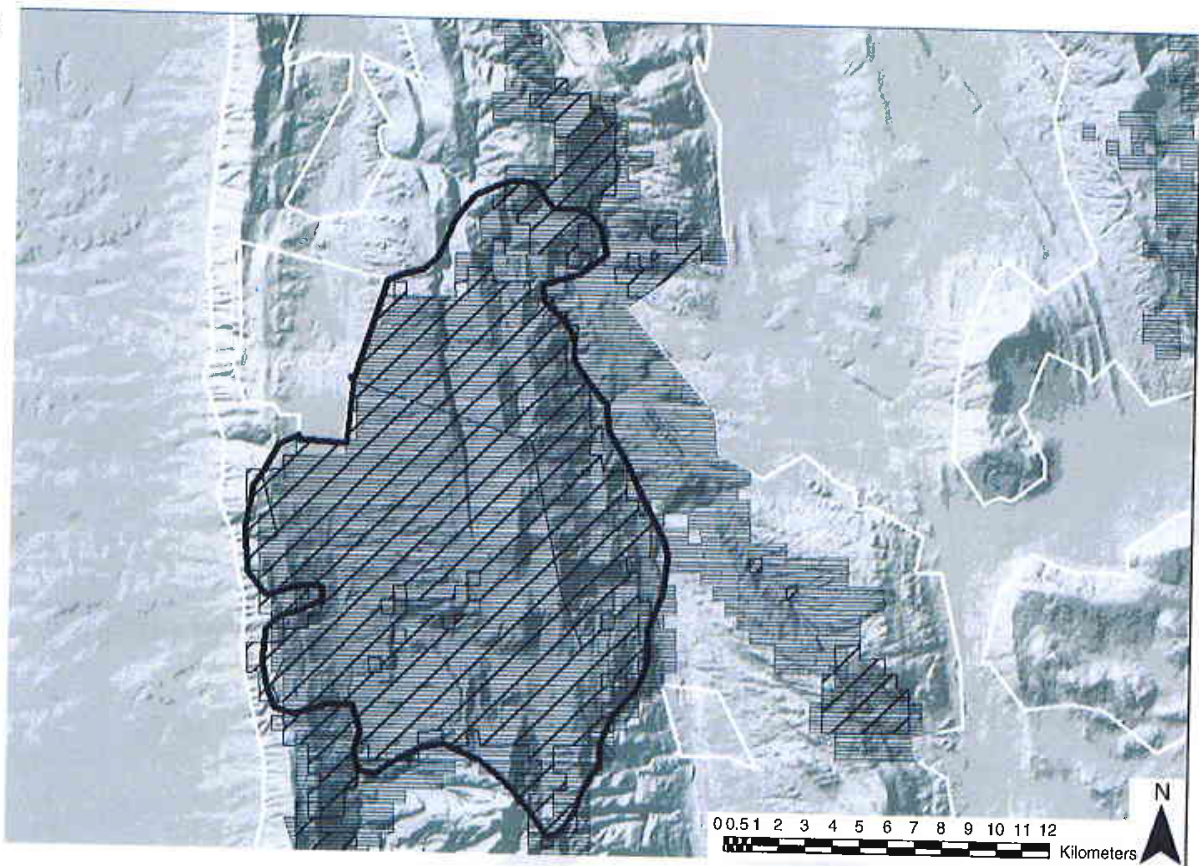

Fig. 3. (Continued)

reflectance of dense, mature fynbos differs from that of the dry senescent grasslands (Wessels et al. 2010) where much of the testing of the Roy algorithm was conducted (Roy and Landmann 2005).

WAMIS detects more small fires than MCD45A1 does, leading to lower levels of omission. The minimum detectable burned area for this product will be in the order of 13-120 ha (Giglio et al. 2009). The success of the WAMIS product over the MCD45A1 product in picking up smaller fires may be because of the integration of active fire map data into the WAMIS product (Giglio et al. 2006). This integration of the different types of fire information available from the MOIDS sensor is achieved through the use of the active fire maps to generate regional probability density functions and to specify prior probabilities, which assists in the selection of both burned and unburned training pixels (Giglio et al. 2009). The fact that fires up to 1000 times smaller than the minimum detectable size of a burned area can be picked up from active fire data (Giglio et al. 2006) allows the WAMIS product to be more sensitive to smaller fires than the MCD45A1 product. In contrast, the MCD45A1 product uses a reflectance-only approach (Roy et al. 2005a) that does not exploit active fire information (Giglio et al. 2009). The exploitation of active fire maps in the 'WAMIS/Giglio' algorithm may well give it more robustness over a wide range of biomes, as speculated by Giglio et al. (2009), as the WAMIS product is more reliable than the MCD45A1 product in the fynbos, which has different pre and post burn conditions from the savanna where most of the testing of the fire products in southern Africa has taken place (Roy and Landmann 2005; Roy et al. 2005b). In addition, the regional stratification of the probability density functions in the WAMIS product help to account for the influence of various vegetation structure and fire types on the post-fire reflectance characteristics (Giglio et al. 2009). The fact that the WAMIS product testing included a vegetation type similar to the fynbos, the Californian chaparral (Giglio et al. 2009), probably improved WAMIS performance in the fynbos.

The difference between these two burned area products was particularly evident when considering the burned areas of large fires (e.g. Fig. 3b). Giglio et al. (2009) would probably attribute the success of the WAMIS product in mapping larger burned areas to 'the inclusion of a region growing phase, which also permits the algorithm to function in the presence of extremely large burned areas', as well as the accurate identification of both burned and unburned pixels through the incorporation of active fire pixels and through the use of both spectral and textural information.

Both products struggle to accurately map the extent of fire events in topographical complex areas, as is seen where WAMIS under-mapped certain fires, such as in the southern Cederberg in February 2008. Both products missed several small to medium fires that had complex boundaries and occurred in topographically complex areas, such as Grootvadersbosch (274 ha, Fig. 3d), Riviersonderend (1695 ha) and Limietberg (516 ha).

\section{Conclusions}

We have compared two MODIS derived burned area products with reliable field-mapped reports for the protected areas in the fynbos biome of South Africa. Our results showed that the two burned area products have different strengths; both may be useful for specific applications. The MCD45A1 had low errors 

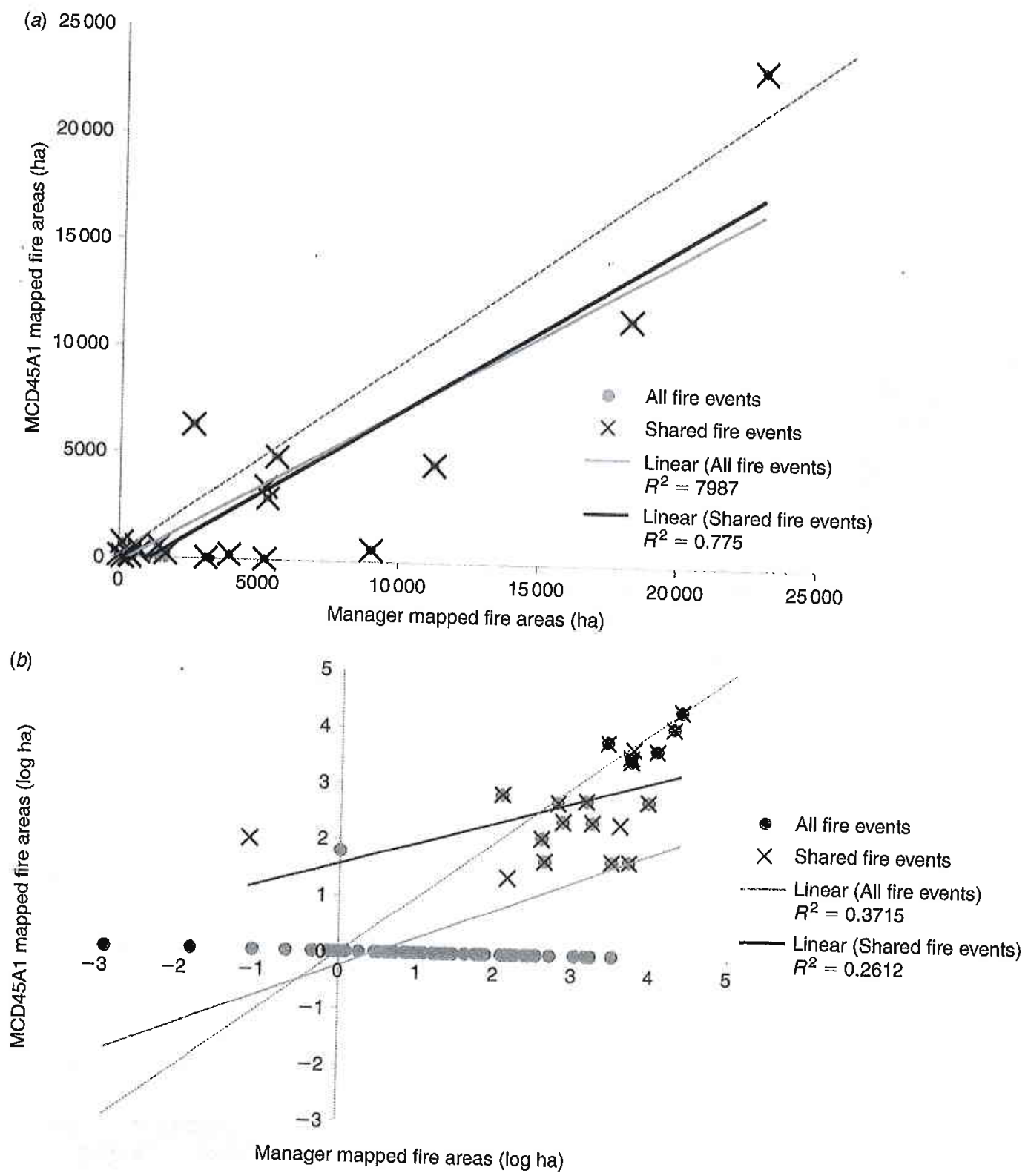

Fig. 4. Regression of the area (ha) of individual fire events, mapped as burned areas by reserve managers (reference dataset) and the
MCD 45A1 product with $(a)$ linear and $(b) \log _{10}$-transformed axis. The least-squares regression is presented as a solid line The deshed $1: 1$ line indicates perfect agreement.

of commission and high consumer's accuracy, but relatively common errors of omission $(40-80.8 \%)$. In contrast, the WAMIS product had lower errors of omission and greater producer's accuracy. These results suggest that the use of the adaptable thresholds by WAMIS led to increased sensitivity in identifying burned areas in the fynbos than the use of the static thresholds applied in the compilation of the MCD45Al product. In addition, the inclusion of a vegetation index in the WAMIS product also yielded improved sensitivity in the fynbos. For users that wish to avoid false positives at the expense of missing many burned pixels, the MCD45A1 will be more useful.
However, the less common omission errors and improved producer's accuracy of the WAMIS product are likely to make it a more useful data source to supplement and check the field mapping of burned areas.

Although WAMIS shows much promise, we would not recommend that it replace the gathering of manager-mapped fire boundaries within the fynbos protected areas. However, WAMIS may be useful in the following contexts: (i) to highlight medium and large fires missed by managers (because of gaps in current institutional arrangements, or fires that rained out deep in wilderness areas before manager became aware of them); 
(ii) to query fire boundaries that managers may have mapped too conservatively; and (iii) to provide a useful indication of fire occurrence and extent (burned area) outside of protected areas. For some studies, such as regional-scale analysis of the fire risk, we suggest that the satellite-derived products are a useful source of data that transcend problems of limited surveying outside formally protected areas or gaps in the records owing to institutional changes. However, one must be cautious to use the satellite-derived products to make inferences about the boundaries, or size, of any particular fire (such as for legal purposes). Over the longer term it would be useful to fine-tune the algorithms to address the small amount of under-mapping and the few medium-sized fires missed by the current WAMIS burned area product.

The application of these burned area detection methods is likely to share the same challenges in Mediterranean shrublands around the world. Shrublands tend to occur on nutrient poor soils and differ structurally from savanna, woodlands and forests (where most evaluations have been conducted). Both factors are expected to influence the performance of the algorithms in similar ways across various Mediterranean ecosystems. Evaluating burned area products across a range of ecosystems around the world would be useful to build confidence in their use in regions and in periods where good evaluation data are lacking.

\section{References}

Bond WJ, Keeley JE (2005) Fire as a global 'herbivore': the ecology and evolution of flammable ecosystems. Trends in Ecology \& Evolution 20, 387-394. doi:10.1016/J.TREE.2005.04.025

Boschetti L, Roy D, Hoffmann AA (2009) MODIS Collection 5 Burned Area Product-MCD45. User's Guide. Ver. 2.0. November 2009. (University of Maryland: College Park MD

Campbell JB (1996) 'Introduction to remote sensing.' (Taylor \& Francis: London)

CapeNature (2009) 'Stewardship operational procedures manual,' (CapeNature: Cape Town)

Chuvieco E, Ventura G, Martin MP, Gomez I (2005) Assessment of multitemporal compositing techniques of MODIS and AVHRR images for bumed land mapping. Remote Sensing of Environment 94, 450-462. doi:10.1016/J.RSE.2004.11.006

Cowling RM (1987) Fire and its role in coexistence and speciation in Gondwanan shrublands. South African Journal of Science 83, 106-112.

de Klerk H (2008) A pragmatic assessment of the usefulness of the MODIS (Terra and Aqua) 1 -km active fire (MOD14A2 and MYD14A2) products for mapping fires in the fynbos biome. International Journal of Wildland Fire 17, 166-178. doi:10.1071/WF06040

Denman KL, Brasseur G, Chidthaisong A, Ciais P, Cox PM, Dickinson RE, Hauglustaine D, Heinze C, Holland E, Jacob D, Lohmann U, Ramachandran S, da Silva Dias PL, Wofsy SC, Zhang X (2007) Couplings between changes in the climate system and biogeochemistry. In 'Climate change 2007; the physical science basis. Contribution of Working Group I to the Fourth Assessment Report of the Intergovernmental Panel on Climate Change'. (Eds S Solomon, D Qin, M Manning, $Z$ Chen, M Marquis, KB Averyt, M Tignor, HL Miller) (Cambridge University Press: Cambridge, UK, and New York) Available at http:// www.ipcc.ch/publications_and_data/ar4 $/ \mathrm{wgl} / \mathrm{en} / \mathrm{ch} 7 . \mathrm{html}$ [Verified
[Viled 12 August 2011]

Díaz-Delgado R, Pons X (2001) Spatial patterns of forest fires in Catalonia (NE Spain) along the period 1975-1995: analysis of vegetation recovery after fire. Forest Ecology and Management 147, 67-74. doi:10.1016/ S0378-1127(00)00434-5

Erasmus Z (2006) Fire management policy and guidelines. CapeNature, Technical Report. (Cape Town, South Africa)

Fielding AH, Bell JF (1997) A review of methods for the assessment of prediction errors in conservation presence/absence models. Environmental Conservation 24, 38-49. doi: $10.1017 / \mathrm{S} 0376892997000088$

Giglio L, van der Werf GR, Randerson JT, Collatz GJ, Kasibhatla PS (2006) Global estimation of burned area using MODIS active fire observations. Atmospheric Chemistry and Physics 6, 957-974. doi:10.5194/ACP-6957-2006

Giglio L, Loboda T, Roy DP, Quayle B, Justice CO (2009) An active fire based burned area mapping algorithm for the MODIS sensor. Remote Sensing of Environment 113, 408-420. doi:10.1016/J.RSE.2008.10.006

Keeley JE, Bond WJ (1997) Convergent seed germination in South African fynbos and Californian chaparral. Plant Ecology 133, 153-167. doi: 10.1023/A:1009748603202

Li Z, Fraser R, Jin J, Abuelgasim AA, Csiszar I, Gong P, Pu R, Hao W (2003) Evaluation of algorithms for fire detection and mapping across North America from satellite. Journal of Geophysical Research 108, 4076. doi: 10.1029/2001JD001377

Manel S, Williams HC, Ormerod SJ (2001) Evaluating presence-absence models in ecology: the need to account for prevalence. Journal of Applied Ecology 38, 921-931. doi: 10.1046/J.1365-2664.2001.00647.X

Mucina L, Rutherford MC (Eds) (2006) 'The vegetation of South Africa, Lesotho and Swaziland. Strelitzia, 19.' (South African National Biodiversity Institute: Pretoria, South Africa)

Rebelo AG, Boucher C, Helme N, Mucina L, Rutherford MC (2006) Fynbos biome. In 'The vegetation of South Africa, Lesotho and Swaziland. Strelitzia, 19'. (Eds L Mucina, MC Rutherford) pp. 52-219. (South African National Biodiversity Institute: Pretoria, South Africa)

Richardson DM, van Wilgen BW, Le Maitre DC, Higgins KB, Forsyth GG (1994) A computer-based system for fire management in the mountains of the Cape Province, South Africa. International Journal of Wildland Fire 4, 17-32. doi: 10.1071/WF9940017

Roy DP, Boschetti L (2009) Southern Africa validation of the MODIS, L3JRC and GlobCarbon burned area products. IEEE Transactions on Geoscience and Remote Sensing 47, 1032-1044. doi:10.1109/TGRS. 2008.2009000

Roy DP, Landmann T (2005) Characterizing the surface heterogeneity of fire effects using multi-temporal reflective wavelength data. International Journal of Remote Sensing 26, 4197-4218. doi:10.1080/ 01431160500112783

Roy DP, Giglio L, Kendall JD, Justice CO (1999) Multi-temporal active-fire based burn scar detection algorithm. International Journal of Remote Sensing 20, 1031-1038. doi: 10.1080/014311699213073

Roy DP, Lewis PE, Justice CO (2002) Burned area mapping using multitemporal moderate spatial resolution data - a bi-directional reflectance model-based expectation approach. Remote Sensing of Environment 83, 263-286. doi: 10.1016/S0034-4257(02)00077-9

Roy DP, Jin Y, Lewis PE, Justice CO (2005a). Prototyping a global algorithm for systematic fire affected area mapping using MODIS time series data. Remote Sensing of Environment 97, 137-162. doi:10.1016/ J.RSE.2005.04.007

Roy D, Frost P, Justice C, Landmann T, Le Roux J, Gumbo K, Makungwa S, Dunham K, DuToit R, Mhwandagara K, Zacarias A, Tacheba B, Dube O, Pereira J, Mushove P, Morisette J, SanthanaVannan S, Davies D $(2005 b)$. The Southern Africa Fire Network (SAFNet) regional burned area product validation protocol. International Journal of Remote Sensing 26, 4265-4292. doi:10.1080/01431160500113096

Shlisky A, Waugh J, Gonzales P, Gonzalez M, Manta M, Santoso H, Alvarado E, Ainuddin Nuruddin A, Rodriguez-Trejo DA, Swaty R, Schmidt D, Kaufmann M, Myers R, Alencar A, Kearns F, Johnson D, Smith J, Zollner D, Fulks W (2007) Fire, ecosystems and people: threats 
and strategies for global biodiversity conservation. Global Fire Initiative Technical Report 2007-2. The Nature Conservancy (Arlington, VA) Available at http://www.nature.org/initiatives/fire/ files/fire_ecosystems_and_people.pdf [Verified 7 January 2011]

Shlisky A, Alencar AA, Nolasco MM, Curran LM (2009) Overview: global fire regime conditions, threats, and opportunities for fire management in the tropics. In 'Tropical Fire Ecology'. (Ed. MA Cochrane) pp. 65-83. (Praxis Publishing Ltd: Chichester, UK)

Sukhinin AI, French NHF, Kasischke ES, Hewson JH, Soja AJ, Csiszar IA Hyer EJ, Loboda T, Conrad SG; Romasko VI, Pavlichenko EA, Miskìv SI, Slinkina OA (2004) AVHRR-based mapping of fires in Russia: New products for fire management and carbon cycle studies. Remote Sensing of Environment 93, 546-564. doi:10.1016/J.RSE.2004.08.011

Trigg S, Flasse S (2001) An evaluation of different bispectral spaces for discriminating burned shrub-savannah. International Journal of Remote Sensing 22, 2641-2647. doi:10.1080/01431160110053185 van Wilgen BW, Forsyth GG (2008) 'The historical effects and future management of fire regimes in the fynbos protected areas of the Western Cape province.' (Cape Nature Report: Stellenbosch, South Africa)

van Wilgen BW, Forsyth GG, de Klerk H, Das S, Khuluse S, Schmitz P (2010) Fire management in Mediterranean-climate shrublands: a case study from the Cape fynbos, South Africa. Journal of Applied Ecology 47, 631-638. doi:10.1111/J.1365-2664.2010.01800.X

Wessels K, Steenkamp K, von Maltitz G, Archibald S (2010) Remotely sensed vegetation phenology for describing and predicting the biomes of South Africa. Applied Vegetation Science 14, 1-19. doi:10.1111/J:1654109X.2010.01100.X

Wilson AM, Latimer AM, Silander JA, Gelfand AE, de Klerk H (2010) A hierarchical Bayesian model of wildfire in a Mediterranean biodiversity hotspot: implications of weather variability and global circulation Ecological Modelling 221, 106-112, doi:10.1016/J.ECOLMODEL. 2009.09.016 


\section{AUTHOR QUERIES}

AQ1: We can keep this as ' $\log _{10}$ '; however, it need only be 'log' (as base 10 is assumed). ' $1 \mathrm{n}$ ' is the natural logarithm. AQ2: Please confirm the place of publication. 